\title{
Youth and domestic violence [Arabic]
}

Population Council

Follow this and additional works at: https://knowledgecommons.popcouncil.org/departments_sbsr-pgy

Part of the Demography, Population, and Ecology Commons, Domestic and Intimate Partner Violence Commons, Family, Life Course, and Society Commons, and the International Public Health Commons How does access to this work benefit you? Let us know!

\section{Recommended Citation}

"Youth and domestic violence," Policy brief. Cairo: Population Council, 2017. [in Arabic] 


\section{توجهات وسلوكيات الشباب المتزوج نحم العنف الأسرى}

\section{الرسائل الاساسية}

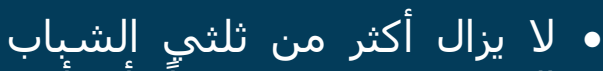

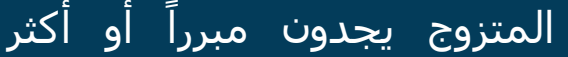
لضرب الزوجة، مما يشير إلى إلى المين

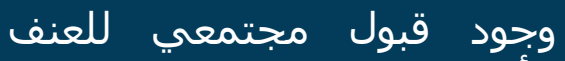
الأسرى بين فئة الشباب.

• يؤثر التعليم على توجه الشابات نحو العنف حيث ترتفع نسب نوابات

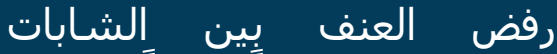
المتعلمات تعليماً ثانوياً مقارنة الماتِ بالشابات الأميات.

• الزواج المبكر قد يصاحبه تعرض العبث العبر

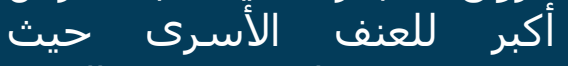

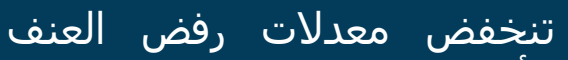
الأسرى لدي الشباب الذين الغين

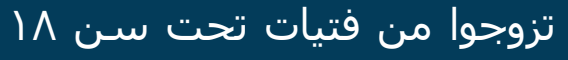

$$
\text { سنة. لرو. }
$$

• ترتفع نسب التعرض للعنف اللفات الأسرى بين الزوجات البعرض اللاتى

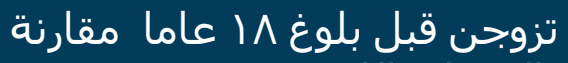
بالزوجات اللاتى تزوجن بعد سـن مارن 1/1 سنة.

• هناك علاقة بين الحصول على خدمة مشورة وفحص مان ما قبل الزواج وعدم تعرض الزورفات للعنف الأسرى.

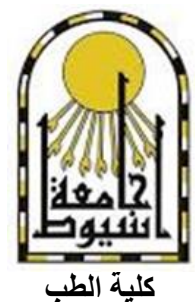

قسم الصحة العامة البة
تتعرض النساء في مصر، منلكن كمنل النساء في معظم

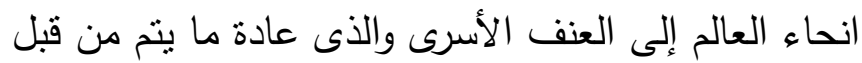

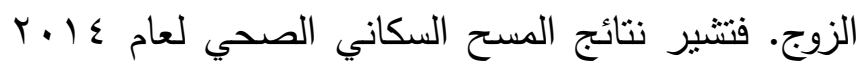
إلى أن • بـ من النساء المتزوجات اللاتى تتزاوح أعمارهن بين 10-9 ؛ قد نعرضن للعنف من قبل الزوج، سواء كان

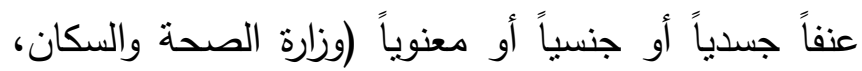

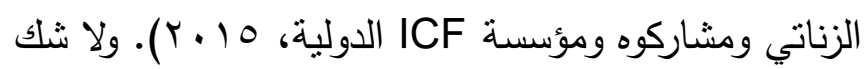

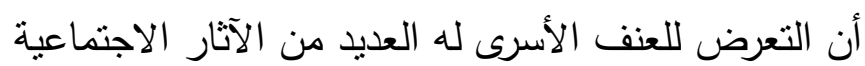

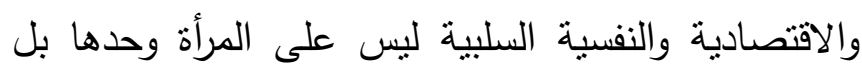

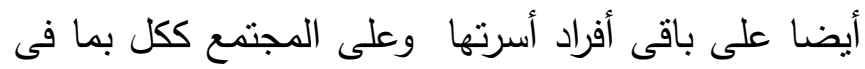
ذلك الاقتصاد القومي للاولة. ونظرا لأن حوالي نصف سكان مصر ينتمون للفئة العمرية

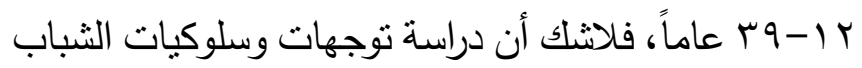

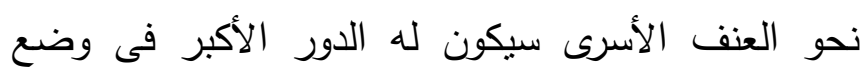

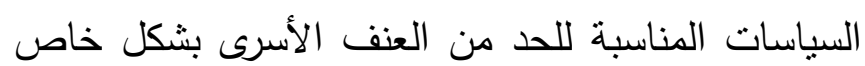

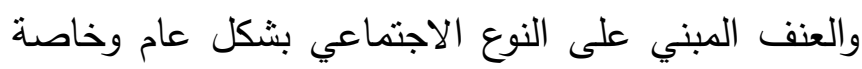

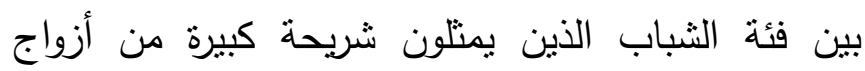

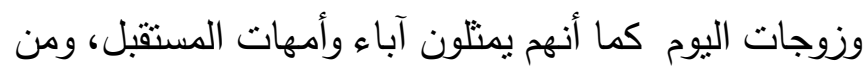
ثم فهم يؤثرون بشكل كبير فى تشكيل القيم والمفاهيم المجتمعية للحاضر والمستقبل. وتأنى هذه الورقة من أجل فئل المساهمة فى وضع السياسات المناسبة للحد من العنف الأسرى وخاصة بين فئة الثباب. 


\section{أولاً: توجهات الشباب المثزوج نحو العنف}

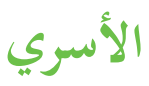

قام مسح النشء والثباب فى مصر بسؤال الششاركين

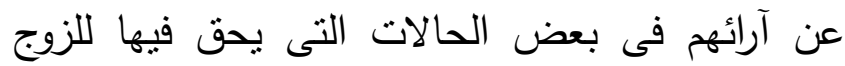
ضرب زوجته وهى (لو حرقت الأكل، لو أهمت الأولاد، لئل

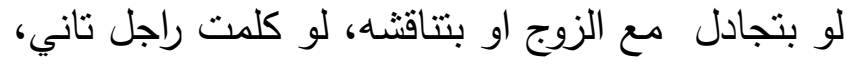

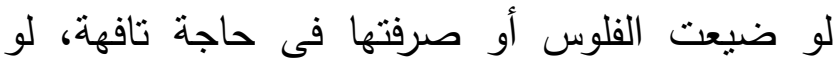

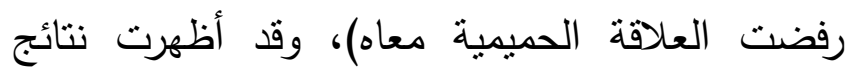

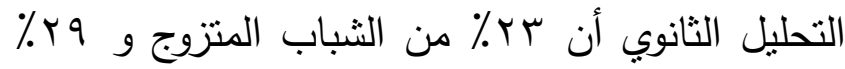

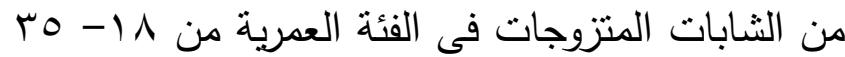

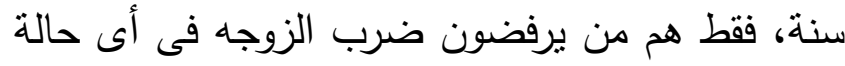
من الحالات السابقة، في حين انه لا يزال أكثر من تلثني

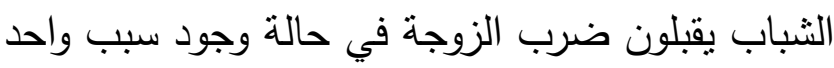

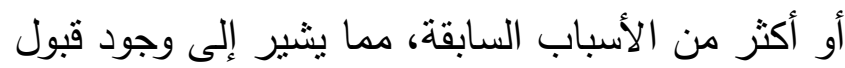
مجتمي للعنف الأسرى داخل فئة الثباب المتزوج.

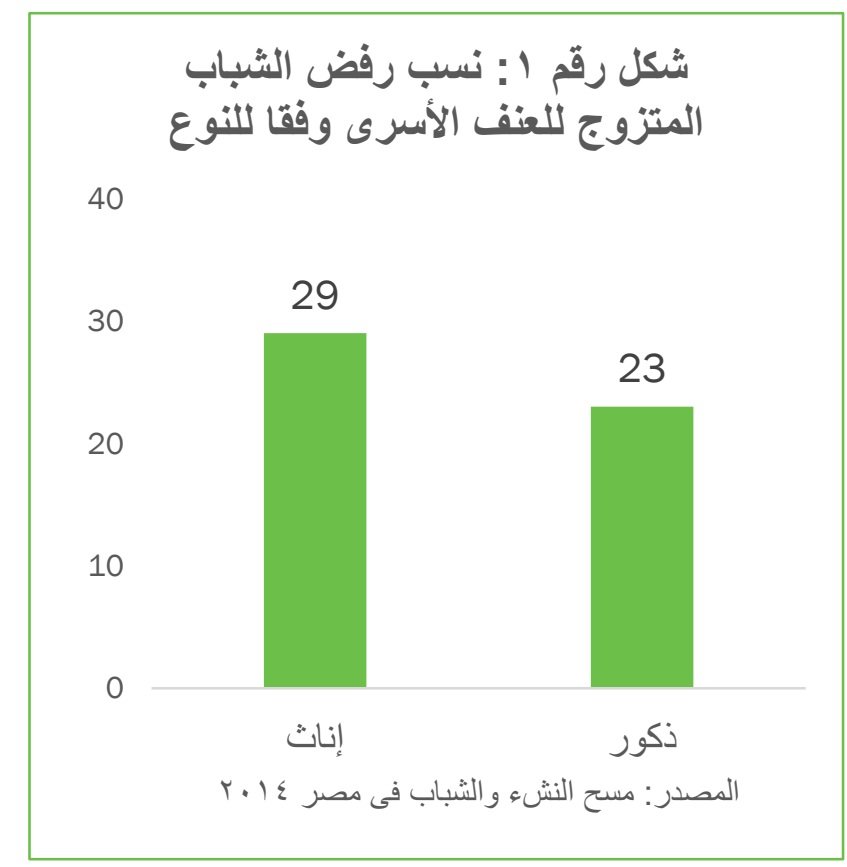

فى اطار مشروع "بناء قدلات الباحشين بقسم الصحة العامة بجامعة أسيوط على إجراء بحوث حول الصحة الانجابية للشباب" والذى تم بالتعاون بين مجلس السكان الدولي وقسم الصحة العامة بكلية طب جامعة أسيوط وبدعم من مؤسسة فورد، قام الباحثون بإجراء مايلي: الي:

1. الحليل ثنانوي لبيانات الدسح التتبعي للنشء

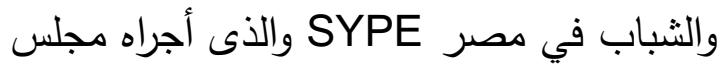
السكان الدولي بالتعاون مع الجهاز المركزي

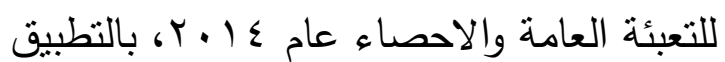
على عينة الثباب المتزوج أو من سبق له الزواج

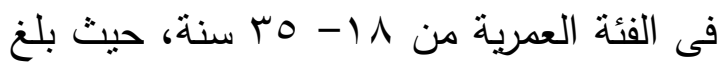

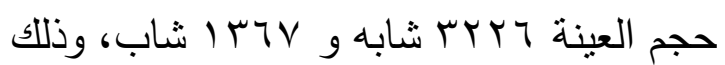
بهذف التعرف على الخصائص الديموجرافية والاجتماعية للثباب المتزوج وعلاقتها بتوجهاتهم الكترفية نحو العنف الأسري.

r. تحليل ثانوي لبيانات مسح الزوجات المراهقات بمحافظتي أسيوط وسوهاج والذى اجراه قسم الصحة العامة بجامعة أسيوط ومجلس السكان

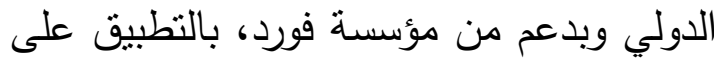

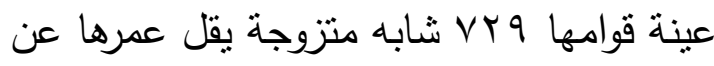
r. r. الدتعلقة بالصحة الإنجابية، وقد ركز النحليل

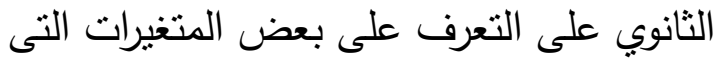
تؤثر على احتمالية تعرض الزوجات المراهقات

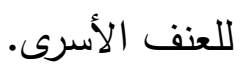


ثانياً: الزوجات المراهقات والتعرض للعنف

الأسرى

كثف التحليل الثانوي لبيانات مسح الزوجات المراهقات

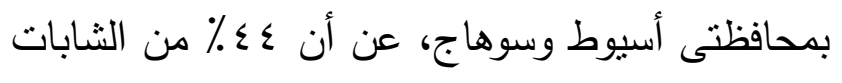

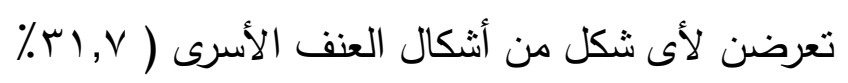

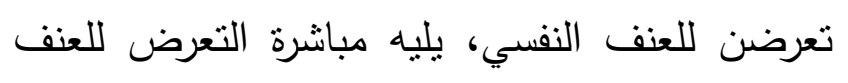

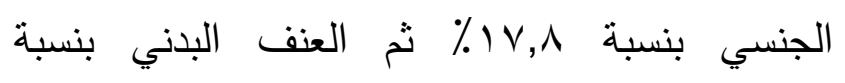
$. * 10, r$

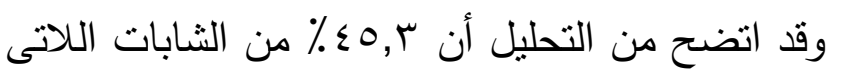

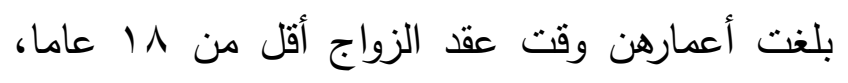
تعرضن لثكل أو أكثر من أثنكال العنف (بدني أو نفسي

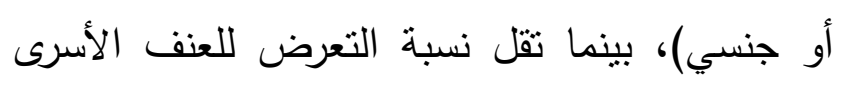

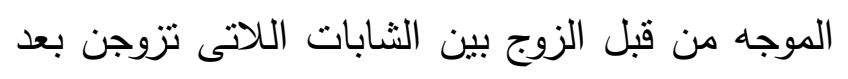

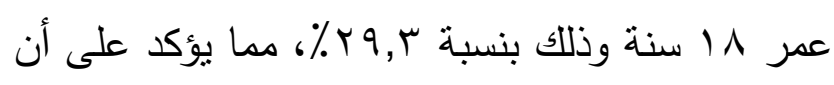

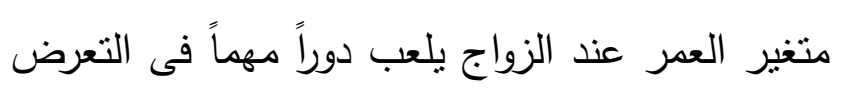
إلى العنف الأسرى.

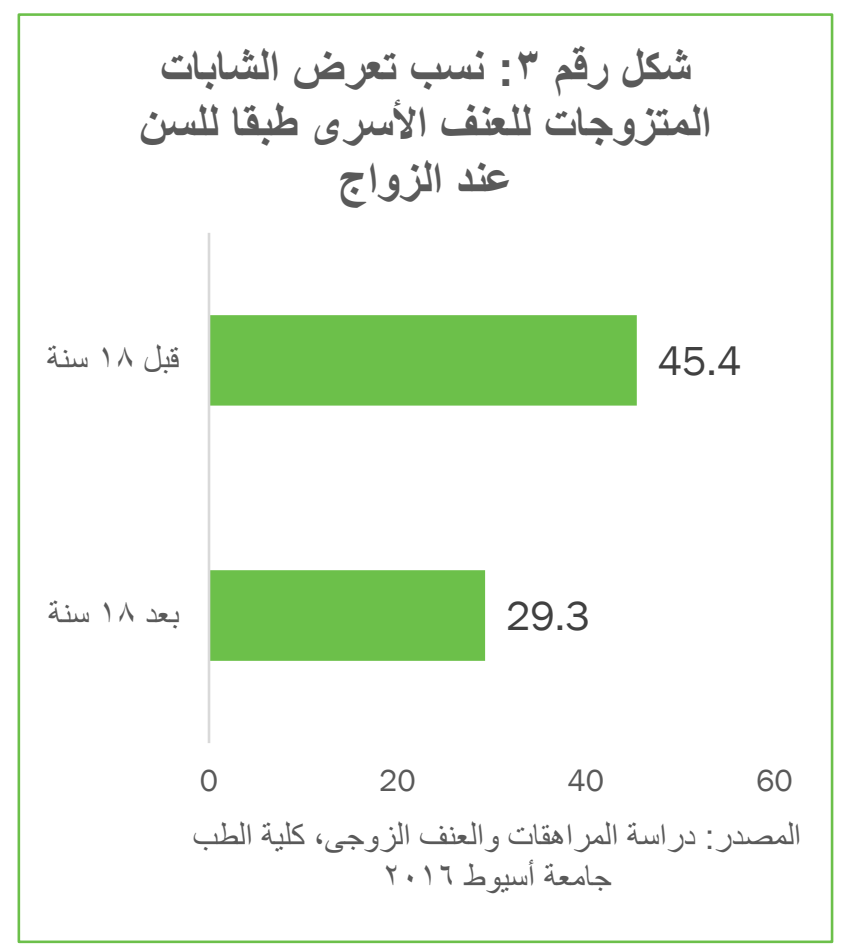

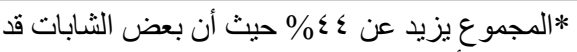
تعرضن لأكثر من نوع من انواع عبث العنف. بعض.

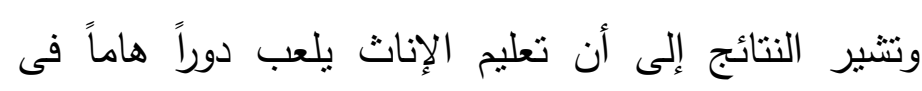

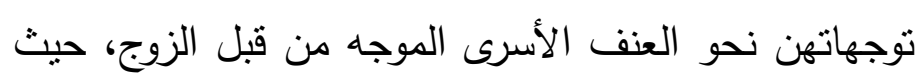

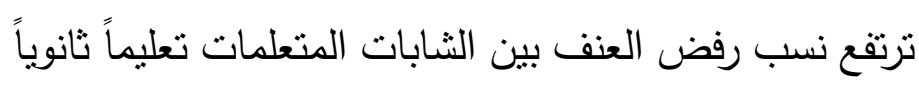

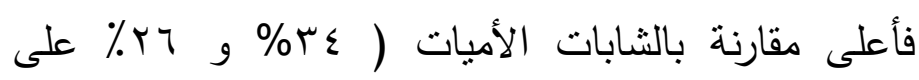

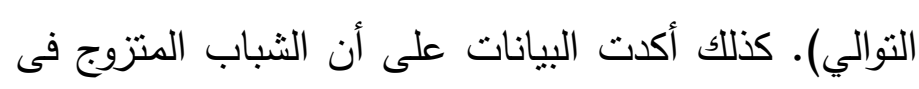

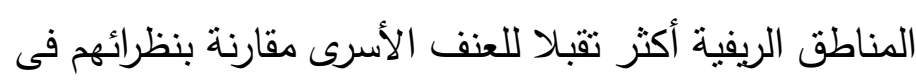

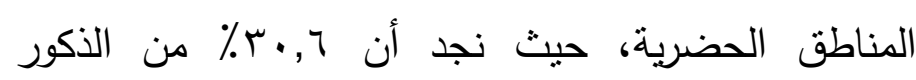

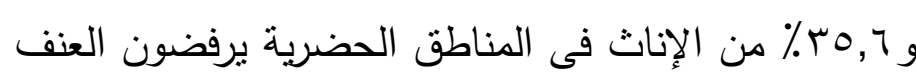

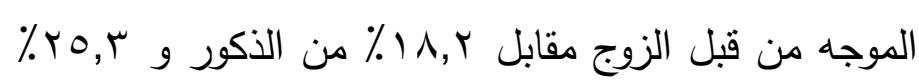

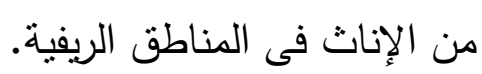

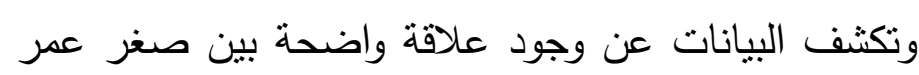

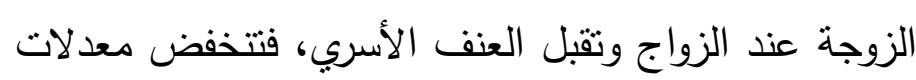

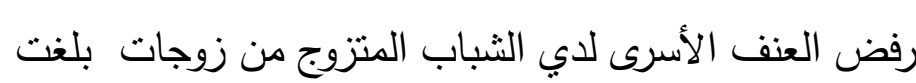

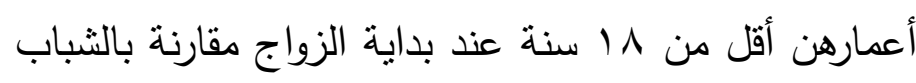

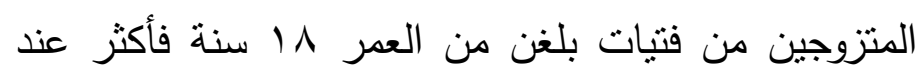

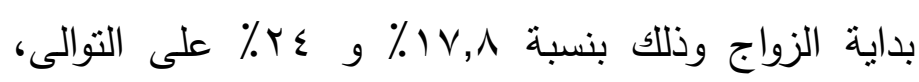

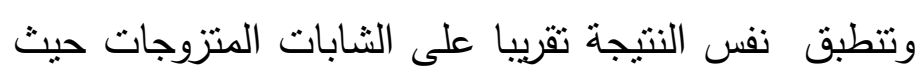
تخفض أيضاً معدلات رفض العنف الأسرى نسبياً بين

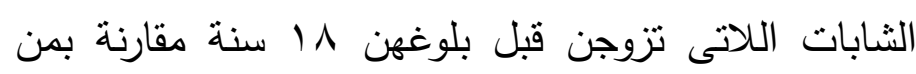

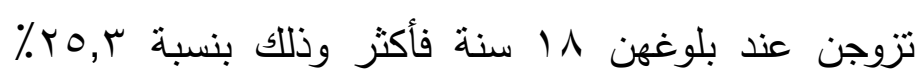

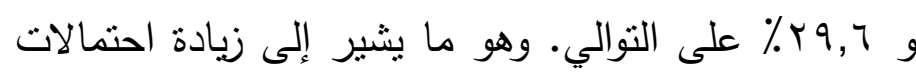

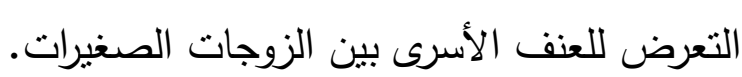

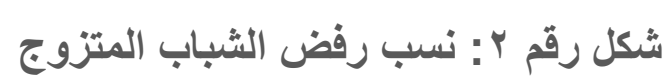
للانف الأسرى وفقا لعمر الزوجه عند الزواج 40

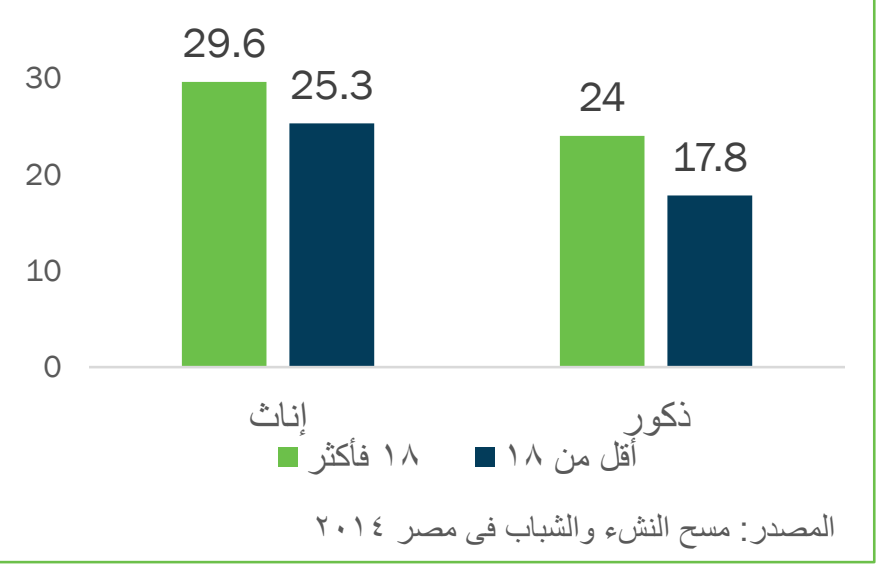


كذللك أوضحت البيانات أن امتلاك الثابات لتليفون

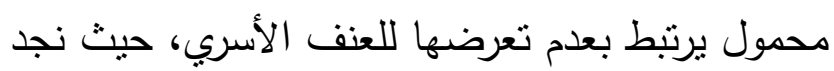

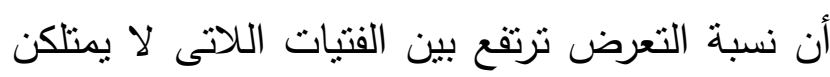

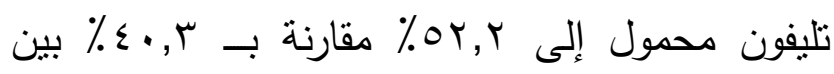

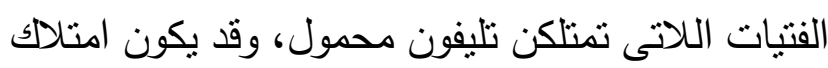
تليفون محمول مؤشر لارتفاع المستوى الاقتصادي للفتاه

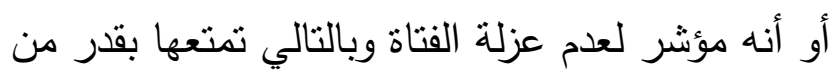

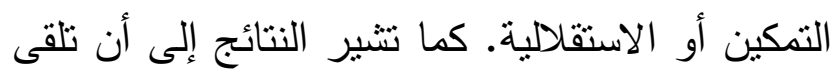

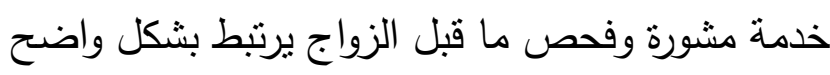

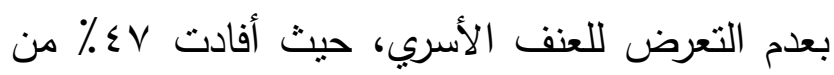

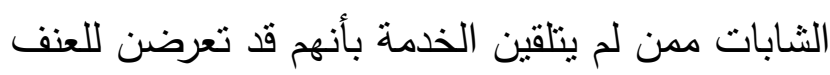

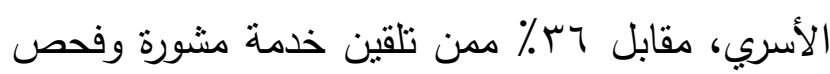

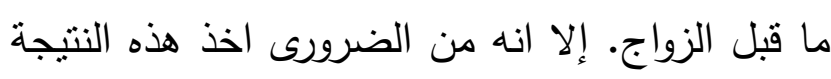

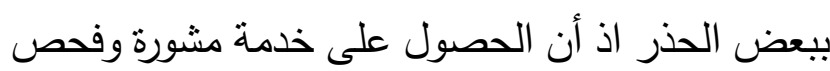

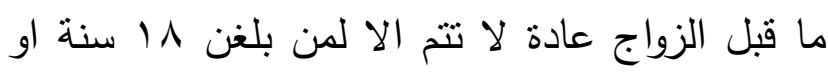

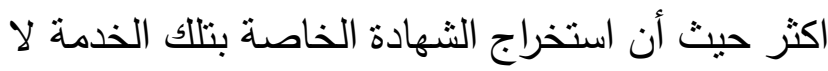
يتم إلا فى المراكز التنابعة لوزارة الصحة والسكان.

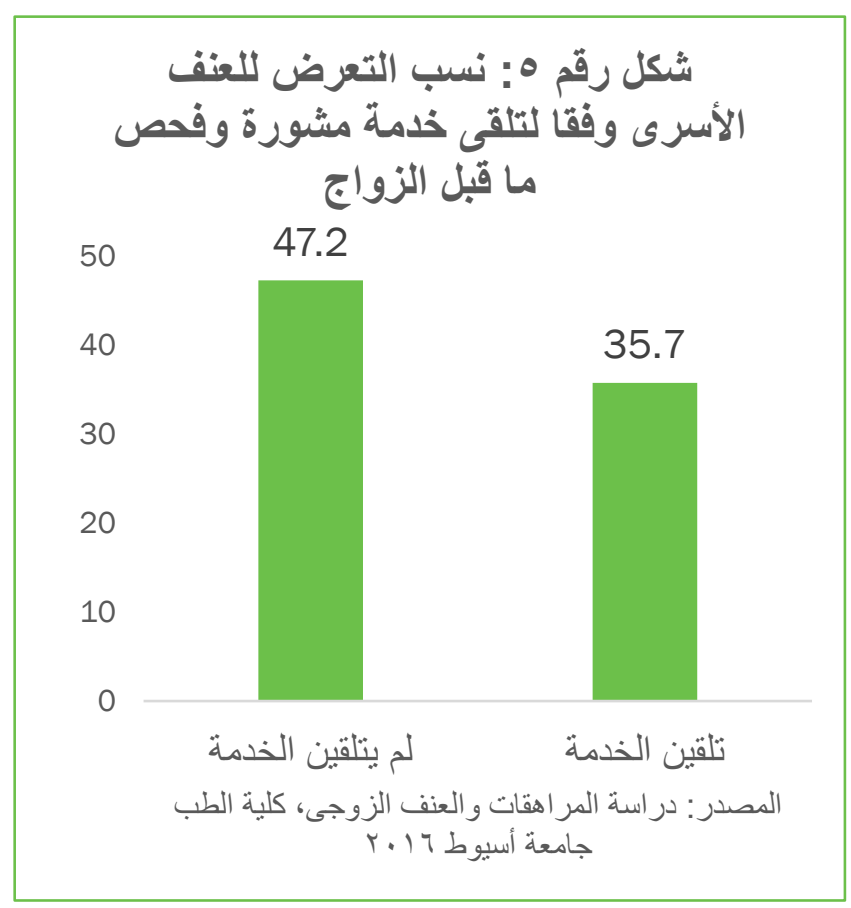

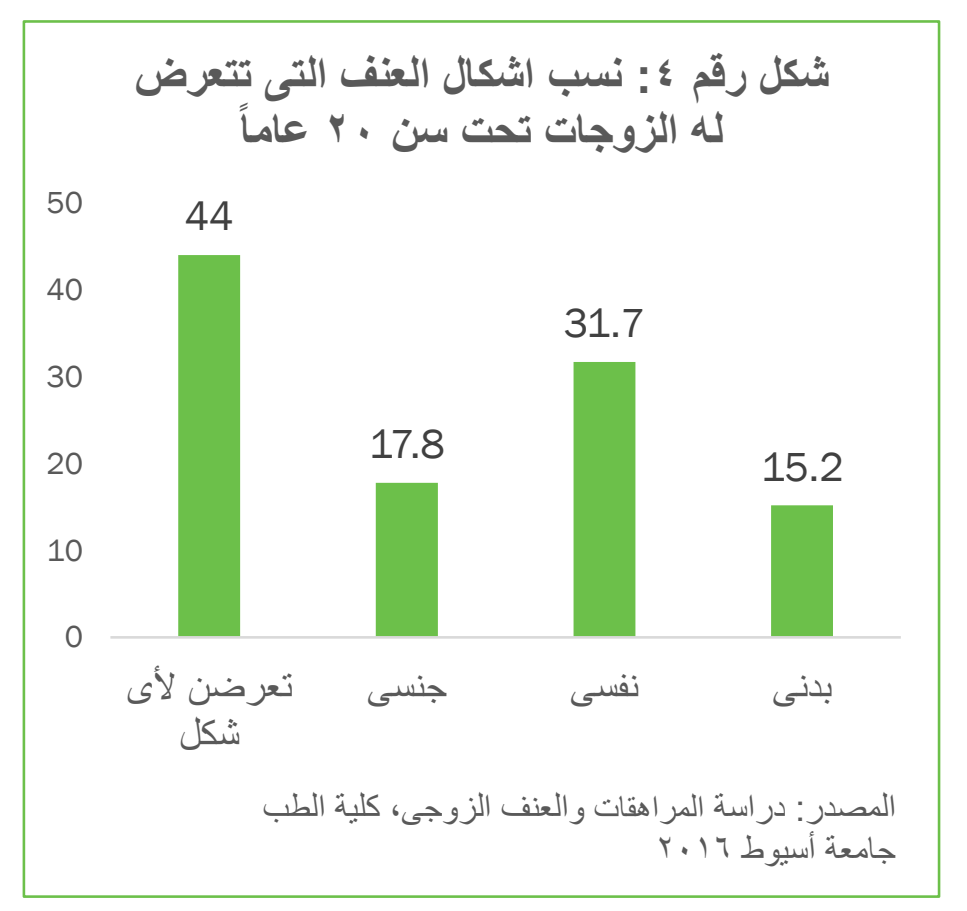

وفيما يتعلق بنوع الأسرة (نووية - ممتدة) التى تعيش فيها

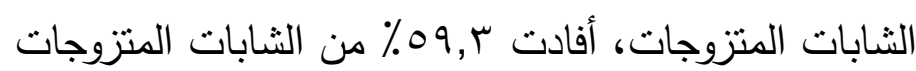

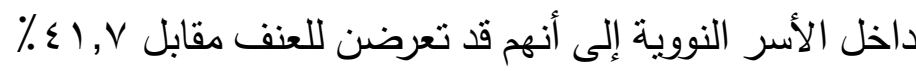

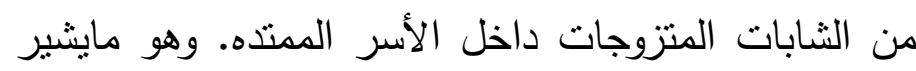

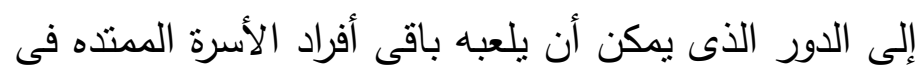

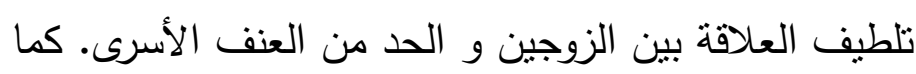

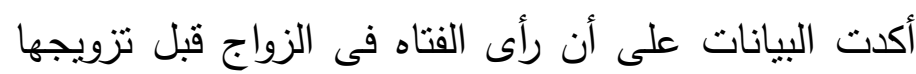

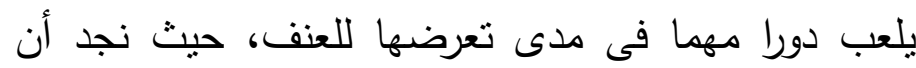

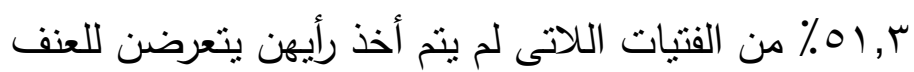

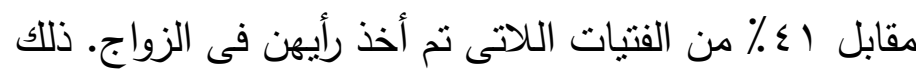
بالاضافة إلى أن مناقثة الفتاة لخططها المستقبلية أثناء فترة

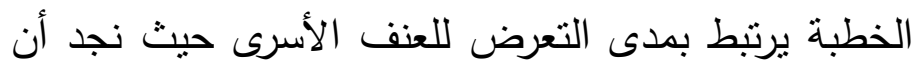
• \% ثقريبا من الشابات اللاتى لم يناقتن خططهن المستقبلية

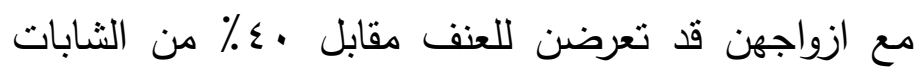
اللاتى ناقشن الخطط المستقبلية، وتؤكد النتيجتين السابقتين على أن اعطاء الفتاة الحرية فى الموافقة على الزواج ومناقتشة

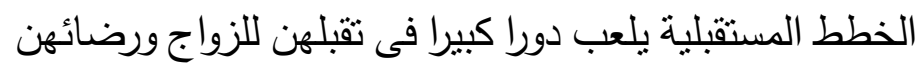
عنه ومن ثم تقل نسب التعرض للعنف الأسري. 


\section{السياسات والبرامج المقترحة للحد من}

القائمة لتتمية المشروعات الصغيرة بين الفتيات ومن ثم تقديم الدعم الفني والمالي للمشروعات الصغيرة ومتتاهية الصغر وخاصة تلك التى تديرها الفنيات.

\section{تحسين الأوضاع التعليمية للفتيات}

لابد من وضع سياسات واضحة وملزمة للحد من تسرب الفتيات من التعليم واستكمال تعليمهن ومحو أميتهن، وقد يتم ذلك من خلال زيادة عدد المدارس الابتدائية والاعدادية والثانوية وخاصة فى المناطق المحرومة (مثال الريف، الوجه القبلى) وكذللك زيادة أعداد مدارس الفصل الواحد والمدارس صديقة الفتيات بالاضافة إلى

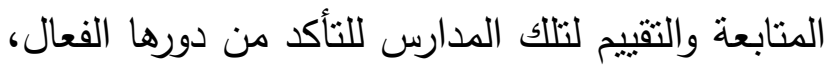
بالاضافة إلى توفير منح ومكافآت رمزية للفنيات اللاتى ينجحن فى استكمال كل مرحلة تعليمية.

\section{توفير الخدمات الصحية والاجتماعية}

ينبغى الارتقاء بخدمة مشورة وفحص ما قبل الزواج وتوسيع نطاق المشورة ليشمل تدريب الزوجين على

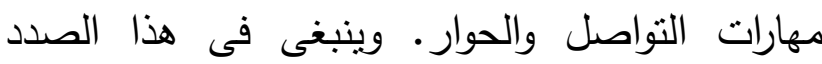
التأهيل الجيد لمقدمي الخدمات الصحية والرائدات الريفيات حول قضايا الدرأة والنوع الاجتماعى والتدريب على تتخيص حالات العنف الأسرى وإحالتها للجهات

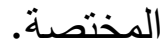

وفيما يتعلق بالنساء المعنفات فلابد من تفعيل وتوفير خذمات الدعم الصحي والنفسي والمشورة للمعنفات وخاصة مراكز استضافة النساء المعنفات، ولابد من عمل تدريبات لمقدمى الخدمات الصحية حول كيفية

\section{العنف الأسري}

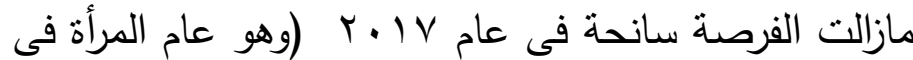

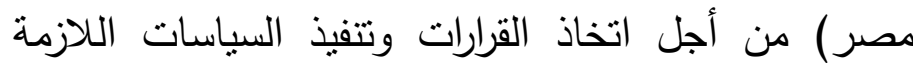
للقضاء على العنف الأسرى ولاسيما بين فئة الثباب، ولاثك الثكات أن ذلك يستلزم التكامل والثراكة بين جميع الجهات سواء

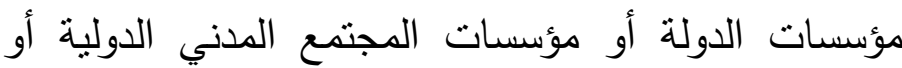
المحلية وكذلك مؤسسات القطاع الخاص من أجل تحقيق الهدف المنشود وهو مجتمع خال من العنف وقائم على مبدأ المساواة بين الجنسين، ويتطلب ذلك مجموعة من السياسات سواء على المستوى التنفيذي أو على المستوى التتريعي والتىى

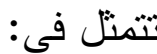

\section{رفع الوعي وتغيير توجهات الشباب}

ويتم ذلك من خلال اعتماد مناهج تعليمية وأنشطة مدرسية تكرس ثقافة المساواة وتكافؤ الفرص بين الجنسين، بالاضافة إلى تتفيذ حملات إعلامية تهدف إلى تغيير الافكار النمطية

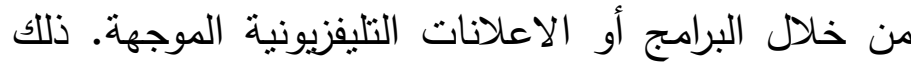
فضلا عن وجود خطاب ديني موجه للثباب ومؤكدا على قيم المساواة بين الجنسين ومناهضة العنف. وينبخى أن يتم ذلك من خلال اثرالك الثباب ذكورا واناثا فى جميع البرامج

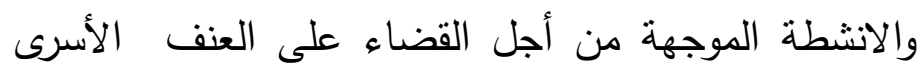
ويمكن الاستفادة فى هذا الثنأن من بعض التجارب السابقة مثل برامج تثقيف القرناء ومن "الثباب إلى الثباب".

\section{التمكين الاقتصادي والاجتماعي للفتيات}

وذللك للحد من ارتفاع نسب الفقر بين الإناث مما يسهم بدوره فى خفض معدلات الزواج المبكر وكذللك إتاحة الفرص وتعزيز قدرتهن على التفاوض والتواصل والاختيار • ويتم ذلك من خلال توفير برامج الدعم المادي للفتيات وتفعيل دور الوحدات 
Mohamed S, Rabee F, Attia M. 2016. "Attitudes of ever married women toward gender-based violence and its determinants". Unpublished paper, Assiut University.

مجلس السـكان الدولى، الجهاز المركزى للتعبئة العامة والاحصاء 10 ـ r. المسح التتبعى للنشء والثباب لعام ع ا ـ r. القاهرة: مجلس السكان الدولى.

وزارة الصــحة والسـكان (مصــر)، الزناتى ومشــاركوه (مصـر)، ومؤسـسـة ICF الدولية. 0 أ. أ : المسـح

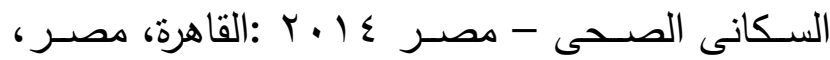
روكفيل، ميربـالند، الولايـات المتحدة الأمريكيـة، وزارة الصحة والسكان ومؤسسة ICF

\section{شيكر وثقدير}

يتقدم مجلس السكان الدولي وقسم الصحة العامة بجامعة أسيوط بالثكر لمؤسسة فورد على دعمها لمشروع "بناء قدرات الباحثين بقسم الصحة العامة بجامعة أسيوط على لجراء بحوث حول الصحة الانجابية للشباب" ، والذى تضمن اجراء التحليلات الاحصائية اللازمة لاخراج هذه الورقة، كما نتقدم بالثكر لفريقي العمل بمجلس السكان الدولي وجامعة أسيوط الذين قاموا باجراء التحليلات الاحصائية وكتابة التقارير التى انبثقت منها هذه الورقة. والشكر موصول للأستاذه رشا حسن مسئول برنامج بمجلس السكان الدولي لاسهاماتها القيمة فى

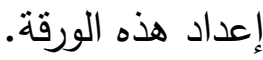

التعامل مع جميع اشكال العنف قبل أو أثناء أو بعد التعرض له. كذلك لابد من نوفير مراكز المساعدة القانونية، وعمل حمات توعية لرفع الوعى بوجود تلك المراكز وكيفية الوصول اليها والاستفادة من خدماتها، واخيراً تفعيل دور مراكز مكافحة العنف ضد المرأة داخل أقسام الثرطة، وخلق بيئة مناسبة للابلاغ عن حوادث العنف.

\section{التشريعات المعنيه بتجريم العنف ضد}
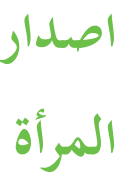

من الضروري وجود قانون معني بتجريم جميع اشكال العنف ضد المرأة والعنف الأسرى على وجه التحديد، حيث يتتاول القانون الاجراءات والاطر المناسبة لكيفية إثبات جريمة العنف الأسرى وذلك لمنع التحايل، فضلا عن ضرورة اتخاذ التدابير اللازمة لحماية ضحايا العنف والثهود.

وفيما يتعلق بزواج الفتيات الصغيرات فانه على الرغم من أن المشرع المصرى قد رفع سن زواج الاناث من 1 إ إلى 11 عاما أسوة بالذكور ، الا ان الثغرات القانونية تحول دون تتفيذ القانون والتحايل عليه بعقد زواج غير موثق، ومن ثم لابد من مراجعة القوانين بحيث يتم اصدار قوانين صارمة تعاقب كل من ابرم عقد زواج تحت السن القانونى (ولو بصورة غير رسمية) وكذلك ولى الامر والزوج والثهود.

Elgiblay O, Darwish M, Aziz M, El Gazzar A, Mahmoud H. 2016. "Spousal violence and its determinants among married adolescent girls". Unpublished paper, Assiut University.

Hassan H, Ismail T, Soliman A. 2016. "Correlates of married men's attitude towards gender- based violence". Unpublished paper, Assiut University. 



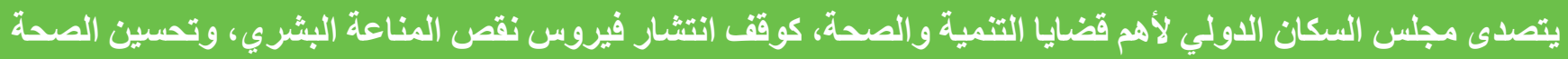

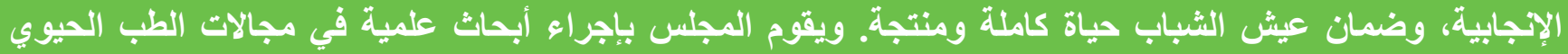

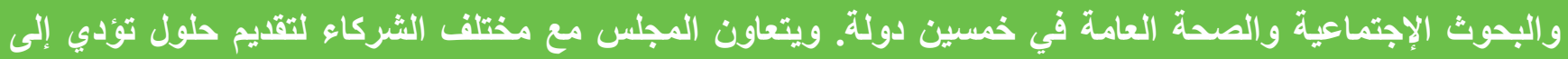

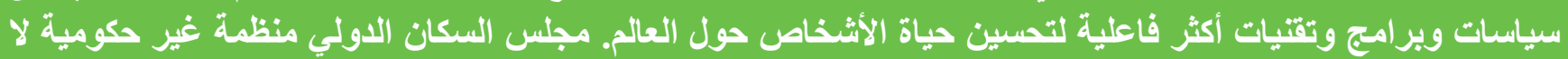

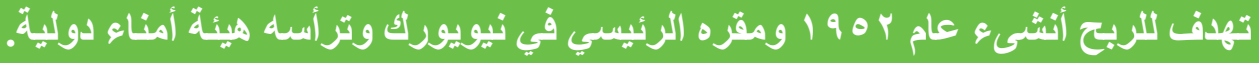

Population Council One Dag Hammarskjold Plaza New York, NY 10017

$$
\begin{aligned}
& \text { مجلس السكان الدولي - مصر ماعر }
\end{aligned}
$$

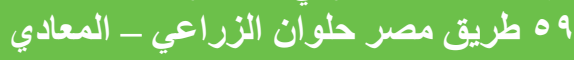

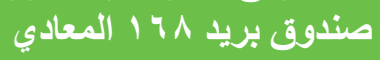

$$
\begin{aligned}
& \text { | القاهزة - مصر برد } \\
& \mid \text { | } \\
& \text { صاتف: } \\
& \text { فاكس:r }
\end{aligned}
$$

Info.egypt@popcouncil.org:البريد الاكتروني الموقع الاكتروني: الاكترني: www.popcouncil.org

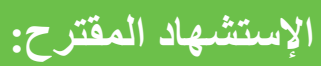

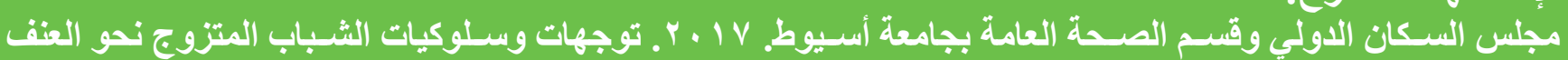
الأسرى ـ القاهرة: مجلس السكان الدولي.

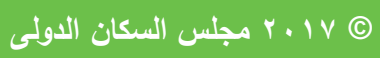

\section{POPULATION COUNCIL}

